\title{
Proses Islamisasi, Perkembangan, dan Eksistensi Islam di Perancis
}

\author{
Suparto Iribaram \\ Institut Agama Islam Negeri (IAIN) al-Fattah Jayapura \\ damiribar@yahoo.co.id
}

Abstract: This paper will describe the historical development of Islam in France, including its existence and problems as a minority. The process of Islamization has long been rising in France, because the French people themselves have long been in contact with Islam, precisely since Islam entered in the 8th century, for about 40 years in the southern part of France, namely the transition period of power from the Umayyad Dynasty to the Dynasty Abbassiyah. Furthermore, though hampered by the Crusades and expansion, the Islamization process in France explicitly began in 1830, when Muslim immigrants came to bring their commodity to France, when the era of North African colonization began. Since that time the population of Muslims in France experienced significant developments. The number of Muslims in France in 2005 has reached 5,000,000 people and there are about 2,500 mosques; the majority of them are from North Africa Sunni. However, the problems faced by French Muslims today are the marginalization of such regulations as the ban on jilbab (hijab), the existence of negative prejudices and fear of terrorism and radicalism.

Keywords: The Historical Development of Islam in France, French Muslims, Muslim Immigrants, Existence and Marginalization Minority. 


\section{Pendahuluan}

Sejarah pertumbuhan dan perkembangan Islam mengalami pasang surut dan periodesasi, yang oleh Harun Nasution membaginya atas lima fase, yaitu 1) klasik (650-1250 M); 2) disintegrasi (1000-1250 M); 3) pertengahan (1250-1800 M); 4) tiga kerajaan besar (1500-1800 M); dan 5) modern (1800-sekarang). ${ }^{1}$ Ketika tiga kerajaan besar Islam sedang mengalami kemunduran pada abad ke-18 M, Eropa Barat justru mengalami kemajuan dengan pesat di berbagai bidang. Tiga kerajaan besar tersebut antara lain, Kerajaan Safawi yang hancur di awal abad ke-18; Kerajaan Mughal hancur pada awal paro kedua abad ke-19 di tangan Inggris yang kemudian mengambil alih kekuasaan di anak benua India; kerajaan Islam terakhir yang masih disegani oleh lawan pada masa itu, Kerajaan Uśmāni di Turki, mengalami kemunduran demi kemunduran, sehingga ia dijuluki sebagai the sick man of Europe (orang sakit dari Eropa). ${ }^{2}$ Melemahnya ketiga kerajaaan Islam itu membuat Eropa dengan mudah dapat menduduki dan menjajah negeri-negeri Islam.

Satu demi satu, negeri-negeri Islam yang sedang rapuh itu jatuh ke tangan Barat. Dalam waktu yang tidak lama, kerajaan-kerajaan Eropa sudah membagi-bagi seluruh dunia Islam. Inggris merebut India dan Mesir. Rusia menyeberangi Kaukakus dan menguasai Asia Tengah, serta Perancis menaklukkan Afrika Utara. Bersamaan dengan itu, maka terjadi migrasi besar-besaran, yakni banyak orang meninggalkan negeri asal mereka untuk mencari kehidupan yang lebih baik di berbagai penjuru dunia. Sejumlah masyarakat muslim lalu meninggalkan negeri-negeri mereka, dan bermigrasi ke negara-negara Barat. Oleh karena itu, dewasa ini para imigran Muslim dapat ditemukan di sejumlah negara seperti di Amerika Serikat, Inggris, Jerman, Norwegia, Italia, Selandia Baru, Kanada dan Perancis. Semua negara yang disebutkan ini Muslim menjadi penduduk minoritas.

1 Harun Nasution, Pembaharuan dalam Islam: Sejarah Pemikiran dan Gerakan (Jakarta: Bulan Bintang, 1975), 13-14.

2 Badri Yatim, Sejarah Peradaban Islam, Cet. I (Jakarta: PT. Raja Grafindo Persada, 1994), 174. 
Di antara negara-negara yang disebutkan di atas, Perancis merupakan negara terluas di Eropa, dan ia sebagai negara tertua ketiga di dunia setelah Ethiopia dan San Marino. Menurut data yang ditemukan, Perancis kini telah berusia lebih 1410 tahun. ${ }^{3}$ Penduduk Perancis berdasarkan sensus tahun 2000, kurang lebih dari 56.045.998 jiwa, ${ }^{4}$ dan 95\% di antaranya beragama Katolik. ${ }^{5}$ Selebihnya, terdapat pemeluk agamaagama lain, misalnya Islam, Tao, Shinto, dan selainnya.

\section{Proses Islamisasi di Perancis}

Proses Islamisasi yang dimaksud dalam sub bahasan ini adalah merujuk pada batasan pengertian yang dikemukakan oleh Ahmad M. Sewang, yakni suatu proses yang tidak pernah berhenti sejak datangnya Islam pertama kali, penerimaan dan penyebarannya lebih lanjut. ${ }^{6}$ Terkait dengan pengertian ini, penulis menemukan data yang akurat bahwa proses Islamisasi di Perancis telah lama berlangsung dan mengalami beberapa periode, serta perkembangan yang cukup siginifikan. Dikatakan bahwa proses Islamisasi sudah lama berlangsung di Perancis, karena masyarakat Perancis sendiri sudah lama mengalami kontak dengan Islam, tepatnya sejak Islam masuk pada abad ke-8 di bagian Selatan Perancis, yakni di saat transisi kekuasaan dari Dinasti Bani Umayyah ${ }^{7}$ ke

3 Iwan Gayo, Buku Pintar Seri Senior: Plus 20 Negara Baru, Cet. XVII (Jakarta: Upaya Warga Negara, 2000), 548.

4 Ibid., 547.

${ }^{5}$ Lihat www.yahoo.com/Islam_Perancis/e-011amd/ep-lan12.htm.

6 Ahmad M. Sewang, "Islamisasi Kerajaan Gowa," Makalah, Bedah Buku yang diselenggarakan oleh Pemda dan MPM PPS UIN Alauddin pada 9 Juni 2005, 1.

7 Dinasti Bani Umayyah mulai terbentuk sesaat setelah terjadinya tahkim pada Perang Shiffin. Dalam sense sejarah dikatakan bahwa sikap Hasan bin Ali menuntut kekhalifahan atas kematian ayahnya, senatiasa diliputi keraguan. Hasan memang kelihatannya tidak memiliki keberanian dan kepahlawan dalam mengambil alih kedudukan ayahnya itu, walaupun ia pernah dinobatkan sebagai khalifah kurang lebih lima bulan lamanya. Dikarenakan ketidak inginan Hasan sendiri dan ketidak populerannya di kalangan Muslimin, maka dengan kesadarannya ia angkat kaki dari kancah perpolitikan dan meninggalkan jabatan kekhalifahan. Sehingga, Bani Umayyah melanjutkan sistem 
Dinasti Bani Abbāsiyah. ${ }^{8}$ Islam berkuasa selama kurang lebih 40 tahun. Demikian pula pada abad ke-10 Islam mencoba memperluas kekuasaan daerah kekuasannya, tetapi gagal sebab di abad pertengahan ini, Islam menghadapi Crusades atau Perang Salib dan akhirnya mereka meninggalkan Perancis. ${ }^{9}$ Demikian pula, bangsa Perancis pernah menginjakkan kakinya di Mesir di saat Napoleon menaklukkan mesir pada tahun $1978 .{ }^{10}$ Penaklukan ini, sebenarnya sudah lama diinginkan oleh raja Louis XIV untuk memudahkan jalur perdagangan melalui Laut Merah dan Laut

kekhalifahan tersebut yang di dalam sejarah disebut sebagai sistem dinasti atau kerajaan, yang khalifah pertamanya adalah Mua'wiyah bin Abū Sufyan. Uraian lebih lanjut, lihat Jalāl al-Dīn al-Suyūti, Tarīkh al-Kulafä’' (Bairūt: Dār al-Kutub al-'Ilmiyah, 1988), 156. Lihat dan bandingkan, Ajid Thohir, Perkembangan Peradaban Islam di Kawasan Dunia Islam: Malacak Akar-akar Sejarah, Sosial, Politik, dan Budaya Umat Islam, Cet. I (Jakarta: Rajawali Press, 2003), 34-35.

8 Dinasti Bani Abbāsiyah, tampil setelah Dinasti Bani Umayyah mengalami ke-munduran dan kehancuran. Ira M. Lapidus secara komprehensif menjelaskan bahwa sekitar tahun 747 M, Abbāsiyah telah siap bergerak. Di beberapa perkampungan di Khurāsan, Abū Muslim, seorang agen Abbāsiyah, berhasil merekrut pendukung dari masyarakat Islam yang dibutuhkannya. Sekitar 3000 pasukan tempur yang telah dikumpulkan Abū Muslim, kini siap menggempur kekuatan Marwan (khalifah ke-8 dari akhir Umayyah). Ringkas sejarah, Marwan (w. 720 M) terkalahkan, namun Daulat al-Abbāsiyah belum berdiri, karena Marwan ketika itu digantikan oleh Yazid II, yakni Yazid bin Malik (w. 724) dan kemudian berpindah lagi ke Hisyam (w. 740 M), yang keduanya masih keturunan Bani Umayyah. Dengan wafatnya Hisyam, dan suksesnya Abū Muslim menggalang perhatian masyarakat, maka semakin meluas pula kebencian masyarakat terhadap Daulat Bani Umayyah dan mayoritas masyarakat menaruh perhatian kepada Banī Hasyīm (keturunan dan keluarga Nabi Saw) yang merupakan alur keturunan Bani Abbas, di mana selama dalam kurun waktu yang lama mereka tidak pernah terlibat dan dilibatkan dalam dunia pemerintahan. Di samping Abū Muslim, Abu al-Abbās al-Shafah yang merupakan tokoh utama Bani Abbās melancarkan propoganda, dan keberhasilannya merebut simpatisan, bermuara pada pelantikannya sebagai khalifah pertama Daulat Abbāsiyah pada tahun $750 \mathrm{M}$. Uraian lebih lanjut lihat Ira M. Lapidus, A. History of Islamic Societies (Sejarah Sosial Umat Islam Bagian Kesatu dan Kedua) terj. Ghufran A. Mas'adi, Cet. I (Jakarta: PT. Raja Grafindo Persada, 1999), 102.

9 John L. Esposito, The Oxford Encyclopedia of the Modern Islam World, Vol. 2 (New York: Oxford University Press, 1995), 28.

${ }^{10}$ Sayyed Hosen Nasr, A Young Moslem's Guide to Modern World (Menjelajah Dunia Modern) terj. Hasti Tarikat (Bandung: Mizan, 1994), 126. 
Tengah menuju ke Timur dan ke India. ${ }^{11}$

Dalam Texbook untuk Perguruan Tinggi Agama Islam/IAIN, juga dijelaskan bahwa Perancis telah mengenal Dunia sejalan dengan penjajahan yang dilakukannya terhadap wilayah-wilayah yang berpenduduk mayoritas Muslim di Aljazair, Maroko, Tunisia, Senegal, Mali, Libanon, Mesir dan selainnya. Seperti negara industri lainnya, Perancis juga membuka kesempatan kepada just arbeiders, yaitu buruh tamu dari Tunisia, Marokko, Aljazair, Turki dan sebagainya untuk bermukin di Perancis. ${ }^{12}$

John L. Esposito menyatakan bahwa kehadiran Islam di Perancis menjadi siginifikan bersamaan dengan kolonialisasi Afrika Utara yang dimulai pada tahun $1830 \mathrm{M}$. Pada pedagang yang dikenal dengan istilah Turcos datang dari Aljazair setelah tahun $1850 \mathrm{M}$, menyusul kemudian imigran Maroko yang bekerja di Dermaga Marseilles bagian Selatan. Selama perang Dunia I, para migran yang berjumlah lebih dari 132.000 orang Afrika, Utara berdomisili di Perancis sebagai pekerja sawah dan buruh di Pabrik senjata, serta lebih dari 15.000 orang diminta untuk terlibat dalam peperangan. ${ }^{13}$

Berdasarkan pada keterangan-keterangan di atas, maka dapat dipahami bahwa proses Islamisasi secara implisit di Perancis, telah dimulai sejak terjadinya Perang Salib, ${ }^{14}$ dan secara eksplisit proses Islamisasi di

${ }^{11}$ Hasan Ibrahim Hasan, Islamic History and Culture (Sejarah dan Kebudayaan Islam) terj. Djahdan Human (Yogyakarta: Kota Kembang, 1989), 351.

12 Tim Penyusun Sejarah dan Kebudayaan Islam Direktorat Jenderal Pembinaan Kelembagaan Agama Islam Departemen Agama (Depag) RI, Sejarah dan Kebudayaan Islam, Jilid II (Ujung Pandang: IAIN Alauddin, 1982/1983), 336.

${ }^{13}$ Esposito, The Oxford Encyclopaedia, 28.

${ }^{14}$ Perang Salib (Crusades) adalah serangkaian peperangan yang terjadi antara umat Kristen dengan umat Muslim pada abad ke-11 sampai abad ke-13. Perang Salib ini merupakan konflik terbesar antara Islam yang tengah berkuasa di sebagian Eropa, Afrika Utara, dan Asia, melawan Kristen yang baru bangkit dan berusaha merebut kota Yerussalem. Interval waktu terjadinya Perang Salib adalah selama dua abad yang telah dilancarkan beberapa kali ekspedisi besar-besaran, dan pada akhirnya kemenangan diraih oleh umat Islam. Atas kemenangan ini, maka pada zaman Dinasti Mamalik, hubungan dagang dengan Perancis dan Italia telah dibuka. Uraian lebih lanjut dan 
Perancis dimulai pada tahun 1830, yakni ketika imigran Muslim berdatangan membawa barang dagangan mereka ke Perancis. Dengan demikian, dapat dikatakan bahwa proses Islamisasi di Perancis pada awalnya melalui jalur peperangan dan proses selanjutnya adalah jalur perdagangan. Dalam masa-masa perkembangannya, proses Islamisasi di Perancis tetap berjalan, namun yang terakhir ini ia berproses melalui jalur dakwah dan perkawinan, karena di sana sudah banyak umat Islam yang menetap.

\section{Perkembangan Islam di Perancis}

Mufti de Marseille warga Perancis dan juga Alumni al-Azhar Kairo ketika berkunjung ke kantor PBNU, ia berkata bahwa Indonesia selalu dibuat contoh Perancis dengan agama Islam yang dikembangkan secara damai dan orang memeluk dengan sendirinya dan di sinilah Islam dikenal sebagai agama universal yang tidak mengenal batas. ${ }^{15}$ Dari pernyataan ini, maka dari satu sisi dapat dipahami bahwa perkembangan Islam di Perancis kelihatannya hampir sama dengan perkembangan Islam di Indonesia. Bekaitan dengan itu, dan untuk menentukan secara pasti pemetaan perkembangan umat Islam di Perancis, maka dapat ditelusuri dari berbagai rujukan sumber sebagai berikut.

1. John L. Esposito memperkirakan perkembangan Islam di Perancis mencapai puncaknya pada tahun $1968 .{ }^{16}$ Sayangnya, John L. Esposito di sini, tidak sempat mengungkap berapa populasi umat Islam di Perancis pada tahun itu.

2. Dalam Textbook untuk Perguruan Tinggi Agama Islam/IAIN, ditemukan data bahwa pada tahun 1981, jumlah umat Islam di

lengkap mengenai Perang Salib, lihat Muhammad Farid Wajdi, Dāirah al-Ma'ârif al-Qarn al-Isyrīn, Jilid V (Beirut: Dār al-Fikr, t.t), 531-532; Yahya Harun, Perang Salib dan Pengaruh Islam di Eropa, Cet. I (Yogyakarta: Usaha Yogyakarta, 1987), 23-25; Yatim, Sejarah Peradaban Islam, 78-79; Thahir, Perkembangan Peradaban Islam, 313.

${ }^{15}$ Lihat pernyataan Mufti de Marseille dalam, Hasyim Muzadi, Lampiran Laporan Pertanggung Jawaban PBNU Periode 1999-2004 (Solo: Panitia Muktamar ke-31, 2004), 22

${ }^{16}$ Esposito, The Oxford Encyclopaedia, 28. 
Perancis berkisar 3.000.000 jiwa. ${ }^{17}$

3. Lebih lanjut, John L. Esposito memberikan data bahwa berdasarkan sensus 1990 jumlah umat Islam di Perancis adalah rinciannya sebagai berikut:

a. Imigran muslim ke Perancis sebanyak 614.207 orang berasal dari Aljazair; sebanyak 576.652 orang berasal dari Maroko; sebanyak 206.336 orang berasal dari Tunisia; dan sebanyak 197.712 orang berasal dari Turki.

b. Khusus imigran Aljazair, mereka telebih dahulu datang dan menjadi warga Perancis, yakni sejak kemerdekan Aljazair, ${ }^{18}$ sehingga populasi mereka (sebelum 1990) sudah berjumlah kurang lebih 500.000 orang.

c. "Perancis Baru", yaitu muslim yang mendapatkan kewarganegaraan akibat kelahiran atau melalui naturalisasi. Mereka ini memiliki akses yang cukup luas untuk berkiprah di masyarakat Perancis.

d. Komunitas Perancis yang memeluk Islam. Komunitas ini memiliki peran penting dalam memberikan mediasi antara masyarakat muslim dengan masyarakat Perancis pada umumnya. Mereka inilah yang secara nasional dan natural dianggap sebagai penduduk asli Perancis yang mengetahui seluk-beluk budaya dan perdaban masyarakat Perancis. ${ }^{19}$

4. Selanjutnya, dinas rahasia Perancis memperkirakan bahwa untuk tahun 2003, ada sekitar 30.000-50.000 orang Perancis yang masuk Islam. ${ }^{20}$

Berdasar pada data-data dan keterangan di atas, maka jumlah keseluruhan umat Islam di Perancis selama dalam kurun waktu tahun 1990-an menurut hasil penjumlahan penulis adalah sebanyak 2.094 .907 orang.

\footnotetext{
${ }^{17}$ Tim Penyusun Depag RI, Sejarah dan Kebudayaan Islam, 336.

${ }^{18}$ Aljazair merdeka pada tahun 1962. Gayo (ed.), Buku Pintar Seri Senior, 426.

${ }^{19}$ Esposito, The Oxford Encyclopaedia, 28-29.

${ }^{20}$ Lihat, http://.yahoo.com/Islam_Perancis/panuasia/e-011amd/ep-lan12.htm.
} 
Jika angka siginifikan ini ditambahkah dengan jumlah umat Islam "Perancis Baru" dan "komunitas Perancis yang memeluk Islam", tentu angka tersebut semakin meningkat, dan diperkirakan mencapai jumlah sekitar 3.000.000. Populasi ini, tidak jauh beda dengan data yang ditemukan dalam Textbook untuk Perguruan Tinggi Agama Islam/IAIN sebagaimana disebutkan sebelumnya.

Bila angka 3.000.000-an tersebut di atas ditambahkan lagi dengan angka 50.000-an sebagaimana perkiraan dinas rahasia Perancis pada tahun 2003, tentu lebih meningkat lagi, dan boleh jadi untuk tahun 2004 lalu, umat Islam di sana mencapai populasi 4.000.000-an orang. Walaupun jumlah populasi ini masih dalam perkiraan penulis, namun dapat saja dijadikan pegangan secara kuantitatif.

Jumlah warga muslim di Perancis sudah mencapai 4-5 juta orang dengan sekitar 2.500 masjid yang sudah berdiri. ${ }^{21}$ Terkait dengan data ini dan sensus tahun 1990 di Perancis, Esposito menyatakan bahwa jumlah laki-laki muslim $60 \%$ dibandingkan dengan perempuan yang mencapai $40 \%$. Akan tetapi, lebih lanjut menurut Esposito bahwa angka ini kemungkinan besar akan berubah mengingat banyaknya imigran perempuan Turki yang masuk ke Perancis. ${ }^{22}$ Dengan demikian, populasi umat Islam di Perancis yang jumlahnya kurang lebih 5 juta pada tahun 2005, sebanding antara laki-laki dan perempuan. Mengingat bahwa umat Islam terus mengalami perkembangan dari tahun ke tahun, terutama melalui jalur dakwah dan pernikahan, maka diperkirakan bahwa untuk tahun-tahun berikutnya, populasi umat Islam di sana memiliki pertambahan yang signifikan. Hanya saja, menurut Esposito, irama dan ritme kehidupan sehari-hari masyarakat Perancis tampak semakin kompetitif dan terkadang diisi dengan konflik di dalam masyarakat yang tidak begitu ramah menyambut keberadaan umat Islam. Di samping itu, norma dan nilai kehidupan di Perancis begitu sulit dimengerti di dalam populasi

\footnotetext{
${ }^{21}$ Namun, Mantan Presiden Dewan Muslim Perancis, Dalil Boubakeur menyebut angka 7 juta. "Muslim Prancis Ingin Ada Banyak Masjid di Negaranya," www.republika. co.id. Diakses pada 28 Maret 2018.

${ }^{22}$ Esposito, The Oxford Encyclopaedia, 29.
} 
yang begitu plural semacam ini. Identitas muslim sebagai sebuah sarana identitas budaya merupakan salah satu di antara tumbuhnya sentimen tersebut. ${ }^{23}$ Walaupun demikian, kelihatan bahwa perkembangan Islam secara kuantitas di Perancis akan terus meningkat, mengingat Islam akan terus dianut oleh mereka yang terlahir dari keturunan muslim yang secara konsisten memegang teguh ajaran agamanya.

\section{Problematika dan Eksistensi Umat Islam di Perancis Dewasa Ini}

Meskipun Islam telah berkembang pesat di Perancis dan mereka hidup secara damai sesama intern umat Islam, bukan berarti bahwa umat Islam di sana hidup damai secara eksteren. Pluralisme masyarakat ekstern (non-muslim), adalah salah satu faktor utama memicu terjadinya konflik di tengah-tengah masyarakat, sekaligus merupakan problematika yang dihadapi oleh umat Islam Perancis dewasa ini. Bermula dari peristiwa 11 September 2001 sebagai tragedi terdahsyat dunia di awal abad ke 21, maka seketika itu pula dua orang muslim Perancis bernama David dan Jerome yang barusan masuk Islam, ditahan karena tuduhan terlibat dalam jaringan terorisme internasional. ${ }^{24}$ Kasus dua pemuda mu'allaf tersebut diangkat sebagai bukti bahwa pemerintahan Perancis kelihatannya memiliki citra (prasangka) negatif terhadap umat Islam yang menetap negara Perancis.

Lebih dari itu, tantangan berat yang dihadapi umat Islam Perancis adalah adanya pelarangan penggunaan Jilbab di sana. Program anti jilbab telah meluas hingga pengusiran muslimah berjilbab di Perancis benar-benar telah diberlakukan. ${ }^{25}$ Larangan berjilbab ini, dalam bentuk lain, juga diberlakukan di berbagai kawasan Eropa lainnya dan

\footnotetext{
${ }^{23}$ Lihat, www.yahoo.com/Perancis-dinasti/e-01lamd/ep-lan12.htm.

${ }^{24}$ Ibid.

${ }^{25}$ Lihat, www.islam.lib.com. Keterangan ini sesuai pernyataan Hj. Muliaty Amin, “Hubungan Islam dan Barat Pasca Peristiwa 11 September 2001," Makalah, PPS S3 IAIN Alauddin (2005), 12.
} 
di Amerika. Fenomena seperti ini, merupakan indikasi bahwa bangsa Eropa, termasuk Perancis memandang Islam sebagai makhātir (sesuatu yang bahaya).

Di sisi lain, masalah utama dibalik keluarnya undang-undang "pelarangan berjilbab" ialah ketakutan pemerintah negara-negara Barat terhadap semakin berkembangnya Islam negara-negara tersebut. Negara-negara Barat (termasuk Perancis) senantiasa berusaha untuk memburukkan citra Islam, di antaranya dengan menggambarkan bahwa Islam mengekang kaum Muslimah dengan aturan-aturan agama yang ketat. ${ }^{26}$ Selanjutnya, Samuneh Fur, seorang wanita Perancis berusia 65 tahun yang memeluk Islam pada tahun 1964 mengatakan, "Undangundang larangan berjilbab ditetapkan untuk menghalangi meluasnya pengaruh Islam di Perancis. Akan tetapi, anak muda Muslim di Eropa kini menyambut jilbab dengan lebih baik dibandingkan dari waktuwaktu yang lampau dan hal ini menimbulkan ketakutan pada msyarakat Eropa." ${ }^{27}$ Hal yang sama, Abu Athrus yang telah tinggal selama 40 tahun di Perancis dan mempunyai anak-anak yang berkewarganegaraan Perancis, berkata, "Anak saya pergi ke sekolah dengan menggunakan jilbab karena itulah yang diperintahkan oleh Tuhan. Oleh karena itu, tidak ada undang-undang yang bisa menolak pakaian ini dan kami akan tetap melaksanakan aturan Tuhan ini." ${ }^{28}$

Berdasar pada pernyataan kedua muslim Perancis di atas, maka dipahami bahwa kaum muslim di Perancis dewasa ini, tetap tampil membuktikan kepatuhannya terhadap ajaran agamanya. Walaupun di sisi lain, berimplikasi pada ada kenyataannya bahwa mereka (umat Islam) di sana mengalami berbagai hambatan dan problematika yang pelik.

Berdasarkan pada kenyataan di atas, maka dapat dipahami bahwa pelarangan berjilbab di Perancis merupakan usaha Barat untuk memaksa umat Islam agar melanggar hukum agama mereka sendiri. Oleh karena

\footnotetext{
${ }^{26}$ Lihat, www.irib/wolrdservice/melayuRADIO/perempuan/anti_jilbab03.htm.

${ }^{27}$ Ibid.

${ }^{28}$ Ibid.
} 
itu, pelarangan berjilbab di Perancis merupakan sebuah ujian bagi umat Islam di Perancis secara khusus, dan sekaligus ujian bagi umat Islam di senatero penjuru dunia secara umum. Implikasi lain yang ditimbulkan terhadap pengamalan ajaran Islam di Perancis menurut Abdul Salam Banesh, seorang warga Perancis asal Maroko yang merupakan imam masjid, mengatakan, "Islam selama ini telah diperkenalkan sebagai musuh Barat, namun kini perkembangan Islam di Barat malah semakin meluas karena Islam merupakan agama yang komprehensif dan mampu menjawab berbagai persoalan kehidupan. Perkembangan Islam inilah yang membuat Barat ketakutan." ${ }^{29}$ Lalu, timbul pertanyaan yang sangat mendasar: ada apa dengan Perancis? Negeri yang dipandang memiliki tradisi intelektual luar biasa dan tradisi demokrasi yang menyejarah ini, tiba-tiba takut akan eksistensi Islam. Padahal, Islam di Perancis telah eksis berabad-abad silam dan penganut agama ini yang multikultural dan multibangsa hidup secara toleran dengan masyarakat non-muslim Perancis.

Perancis harus ingat, bahwa terhadap sejarah kaum muslimin yang telah berjasa membebaskan Raja Perancis I dari tangkapan musuhnya pada pertempuran Pavia tahun 1525. ${ }^{30}$ Namun, Azyumardi Azra menyatakan, "Kalau orang Perancis bertingkah sinis, itu memang sudah menjadi bagian sejarah mereka, tetapi kalau Yahudi berlaku sinis, barulah berita." ${ }^{31}$ Berdasarkan pada pernyataan ini, kiranya sangat tidak bijak dan tidak arif, bilamana masyarakat dan apalagi pemerintah Perancis dewasa ini, tetap menganggap Islam sebagai musuh, serta menjadikan Islam sebagai agama yang termarginalkan.

Walaupun dalam kenyataannya pemerintah Perancis dan sebagian masyarakat non-Muslim Perancis tetap menganggap Islam sebagai sesuatu yang negatif, tentu di balik itu semua memiliki nilai-nilai positif

${ }^{29}$ Ibid. Lebih lengkap, lihat www.yahoo.com/islamPerancis/2.htm. Dikutip tanggal 23 Febuari 2018

${ }^{30}$ Lihat, http://www.yaho.com/islampranciz/e-011lamd/ep-lan12.htm.

${ }^{31}$ Azyumardi Azra, Pergolatan Politik Islam: Dari Fundamentaslisme, Modernisme hingga Post-Modernisme, Cet. I (Jakarta: Paramadina, 1996), 215. 
bagi citra Islam. Kenyataannya, Islam di Perancis dewasa ini tetap eksis, bahkan terus berkembang walaupun mereka harus berlawanan dengan masyarakat non-muslim yang fanatik. Dalam praktik keagamaan seharihari, Aslam Timur, Sekjen Dewan Muslim, menyatakan bahwa aliran Islam di Perancis juga banyak mulai dari Wahabi, Salafi, Ikhwanul Muslimin, Jama'ah Tabligh, dan lain-lain yang hidup dengan rukun. ${ }^{32}$ Namun, dalam pandangan penulis bahwa praktik keagamaan sehari-hari umat Islam Perancis tampak pada pola keberagamaan yang mayoritas menggunakan mażhab Sunni karena mayoritas mereka berasal dari Afrika Utara yang kental dengan mażhab Sunni.

Terbangunnya masjid-masjid di Perancis yang jumlahnya sampai 2.500 buah, ${ }^{33}$ juga merupakan salah satu indikasikan bahwa kaum Muslim Perancis dewasa ini antusias dalam menjalankan ibadah-ibadah secara rutin, terutama shalat berjamaah. Praktis bahwa ajaran Islam yang lain, semisal puasa dan zakat juga terlaksana dengan baik.

\section{Kesimpulan}

Berdasar pada permasalahan yang telah ditetapkan dan keterkaitannya dengan uraian-uraian yang telah dipaparkan maka dapat dirumuskan beberapa kesimpulan sebagai berikut.

Proses Islamisasi di Perancis diperkirakan bermula sejak terjadinya Perang Salib, yakni sekitar abad ke-11 sampai ke-13 M, kemudian proses Islamisasi tersebut berlanjut pada 1830, yakni ketika imigran muslim berdatangan membawa barang dagangan mereka ke Perancis. Yang pertama, disebut proses Islamisasi melalui jalur peperangan, dan yang kedua disebut proses Islamisasi melalui jalur perdagangan. Pada masa-masa berikutnya, proses islamisasi di Perancis melalui jalur dakwah dan jalur perkawinan. Perkembangan Islam di Perancis mencapai puncaknya pada tahun 1968, dan terus berkembang sampai mencapai angka 3.000.000

\footnotetext{
${ }^{32}$ Lihat pernyataan Aslam dalam http://www.yahoo.com/Perancis-dinasti/e-01lamd/ ep-lan12.htm.

${ }^{33}$ Ibid.
} 
jiwa antara tahun 1981-1990, serta sekitar 4.000.000 jiwa pada tahun 2004. Memasuki tahun 2005, populasinya mencapai angka 5.000.000 jiwa. Mengingat bahwa umat Islam terus mengalami perkembangan dari tahun ke tahun, terutama melalui jalur dakwah dan pernikahan, maka diperkirakan bahwa untuk tahun-tahun berikutnya, populasi umat Islam di Perancis mengalami perkembangan yang signifikan secara kuantitatif.

Seiring dengan pekembangan Islam Perancis, ternyata umat Islam di sana dewasa ini, menghadapi problematika yang cukup pelik, terutama adanya pelarangan penggunaan Jilbab bagi kaum muslimah. Pelarangan berjilbab di Perancis, ditengarai sebagai usaha Barat untuk memaksa umat Islam agar melanggar hukum Islam. Walaupun demikian, kelihatan bahwa umat Islam di Perancis dewasa ini tetap eksis, dan mampu bertahan hidup melawan situasi dan kondisi yang mengitarinya. Mereka senantiasa geliat dan antusias dalam menjalankan ajaran agamanya, terutama ibadah-ibadah secara rutin semisal shalat, puasa dan zakat, serta selainnya.

Berdasar pada rumusan kesimpulan di atas, maka hasil pembahasan ini berimplikasi pada pentingnya pelacakan lebih lanjut tentang eksistensi Islam di Perancis. Implikasi lainnya adalah, semakin menarik untuk ditelusuri akar sejarah Islam di Perancis dan "denyut jantung" pertumbuhan serta perkembangannya, sebab Islam di sana masih menjadi agama yang penganutnya minoritas bila dibandingkan dengan agama Katolik. 


\section{Daitar Pustaka}

Azra, Azyumardi. Pergolatan Politik Islam: Dari Fundamentaslisme, Modernisme hingga Post-Modernisme. Cet. ke-1. Jakarta: Paramadina, 1996.

Esposito, John L. The Oxford Encyclopedia of the Modern Islam World, Vol. 2. New York: Oxford University Press, 1995.

Gayo, Iwan. Buku Pintar Seri Senior; Plus 20 Negara Baru. Cet. XVII. Jakarta: Upaya Warga Negara, 2000.

Harun, Yahya. Perang Salib dan Pengaruh Islam di Eropa. Cet. I, Yogyakarta: Usaha Yogyakarta, 1987.

Hasan, Ibrahim Hasan. Islamic History and Culture (Sejarah dan kebudayaan Islam), terj. Djahdan Human. Yogyakarta: Kota Kembang, 1989.

Lapidus, Ira M. A History of Islamic Societies (Sejarah Sosial Umat Islam Bagian Kesatu dan Kedua), terj. Ghufran A. Mas'adi. Cet. I, Jakarta: PT. Raja Grafindo Persada, 1999.

Muzadi, Hasyim. Lampiran Laporan Pertanggung Jawaban PBNU Periode 1999-2004. Solo: Panitia Muktamar ke-31, 2004.

Nasr, Sayyed Hosen. A Young Moslem's Guide to Modern World (Menjelajah Dunia Nodern) terj. Hasti Tarikat. Bandung: Mizan, 1994.

Nasution, Harun. Pembaharuan dalam Islam: Sejarah Pemikiran dan Gerakan. Jakarta: Bulan Bintang, 1975.

Sewang, Ahmad M. "Bedah Buku Islamisasi Kerajaan Gowa." Makalah. Bedah Buku yang diselenggarakan oleh Pemda dan MPM PPS UIN Alauddin, pada 9 Juni 2005.

al-Suyūti, Jalāl al-Dīn. Tarìkh al-Kulafầ. Beirūt: Dār al-Kutub al-'Ilmiyah, 1988.

Tim Penyusun Textbook Sejarah dan Kebudayaan Islam Direktorat Jenderal Pembinaan Kelembagaan Agama Islam Departemen Agama 
RI. Sejarah dan Kebudayaan Islam, Jilid II. Ujung Pandang: IAIN Alauddin, 1982/1983.

Thohir, Ajid. Perkembangan Peradaban Islam di Kawasan Dunia Islam: Malacak Akar-akar Sejarah, Soaial, Politik, dan Budaya Umat Islam. Cet. I. Jakarta: Rajawali Press, 2003.

Wajdi, Muhammad Farid. Dāirah al-Ma'ârif al-Qarn al-Isyrīn, Jilid V. Beirut: Dār al-Fikr, t.t.

Yatim, Badri. Sejarah Peradaban Islam. Cet. II. Jakarta: PT. Raja Grafindo Persada, 1994.

\section{Data Internet:}

http://.www.yahoo.com/islamPerancis/2.htm.

http://www.yahoo.com/Perancisi/e-01lamd/ep-lan12.htm

http://.yahoo.com/Islam_Perancis/e-011amd/ep-lan12.htm

http://.yahoo.com/Islam_Perancis/panuasia/e-011amd/ep-lan12.htm

http://ww.irib/wolrdservice/melayuRADIO/perempuan/anti_jilbab03.htm http://www.islam.lib.com/htm.

http://www.yaho.com/islampranciz/e-011lamd/ep-lan12.htm

http://www.yahoo.com/pernyataan_Aslam.Perancis-dinasti/e-01lamd/ ep-lan $12 . h$ tm

http://www.yahoo.com/Perancis-dinasti/e-01lamd/ep-lan12.htm http://www.republika.co.id 
